Supplement of Atmos. Meas. Tech., 14, 3395-3426, 2021

https://doi.org/10.5194/amt-14-3395-2021-supplement

(C) Author(s) 2021. CC BY 4.0 License.

(c) (i)

Atmospheric
Measurement
Techniques

Supplement of

\title{
Optimal use of the Prede POM sky radiometer for aerosol, water vapor, and ozone retrievals
}

Rei Kudo et al.

Correspondence to: Rei Kudo (reikudo@mri-jma.go.jp)

The copyright of individual parts of the supplement might differ from the article licence. 

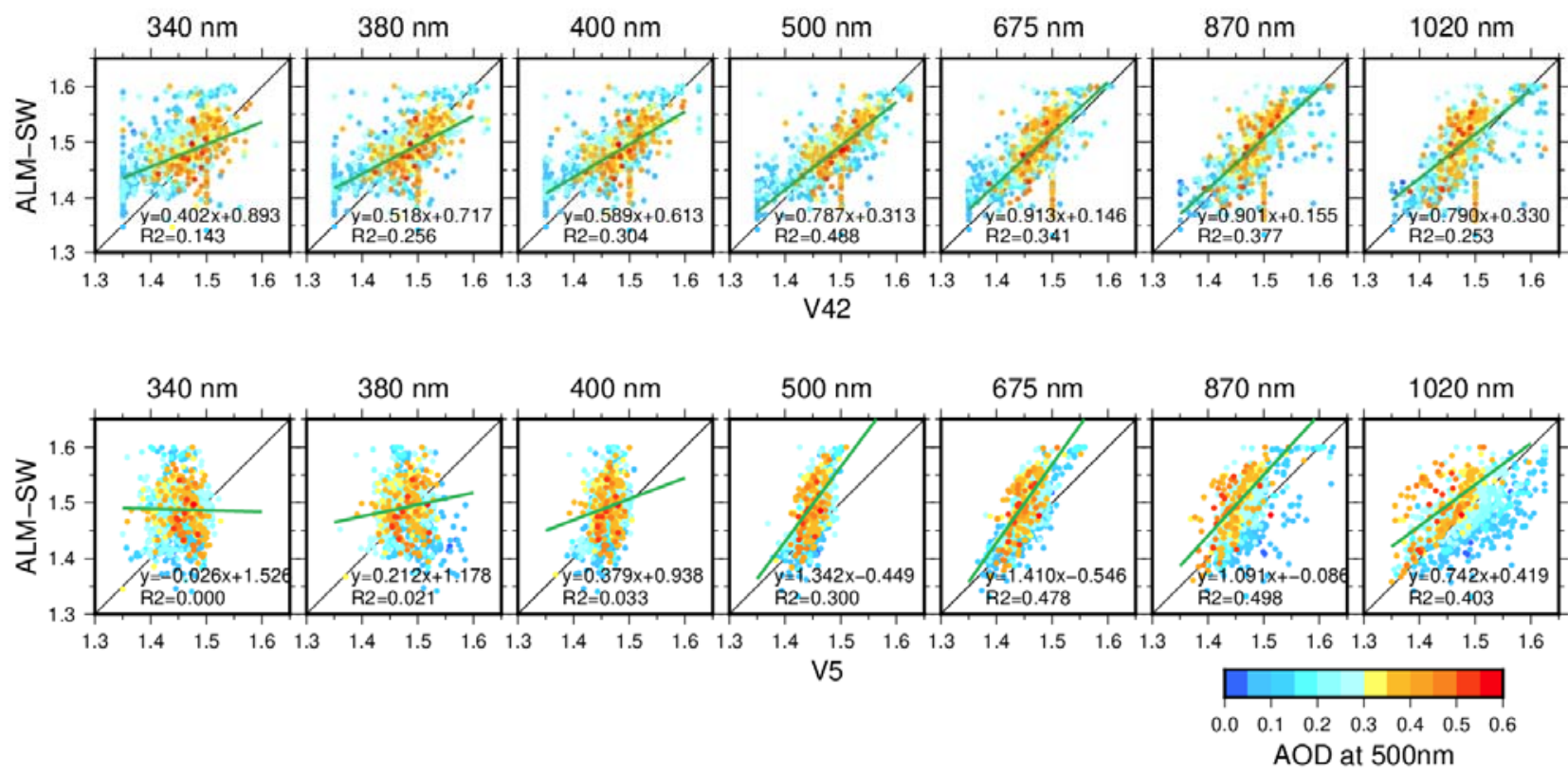

Figure S1: Comparisons of the real part of the refractive index between ALM-SW, V42, and V5. Colors indicate the aerosol optical depth at $500 \mathrm{~nm}$. " $y=a x+b$ " and "R2" are the linear fitting and the coefficient of the determination for the data of the aerosol optical depth more than 0.3 . 

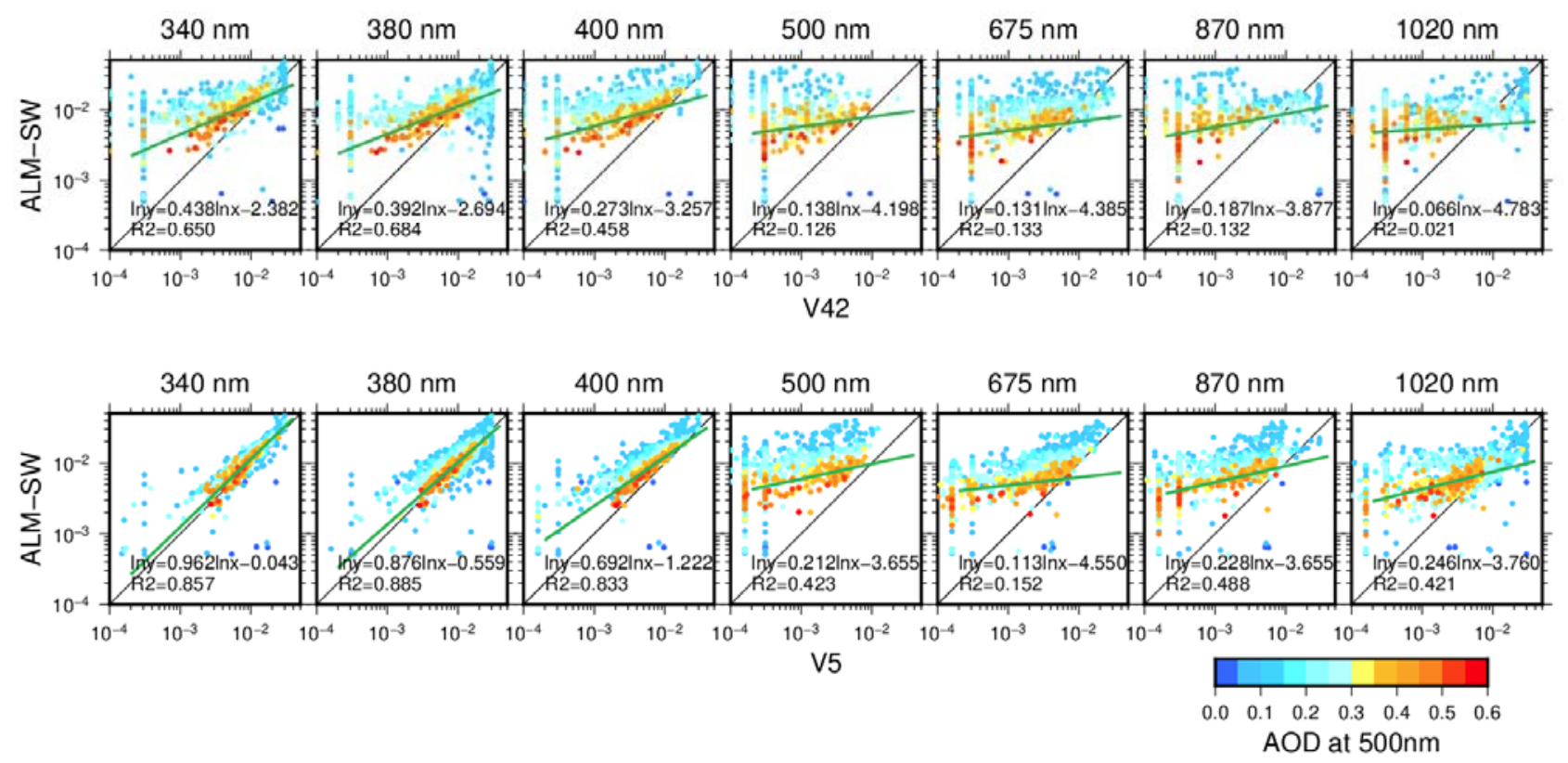

Figure S2: Comparisons of the imaginary part of the refractive index between ALM-SW, V42, and V5. Colors indicate the aerosol optical depth at $500 \mathrm{~nm}$. " $y=a x+b$ " and "R2" are the linear fitting and the coefficient of the determination for the data of the aerosol optical depth more than 0.3 . 

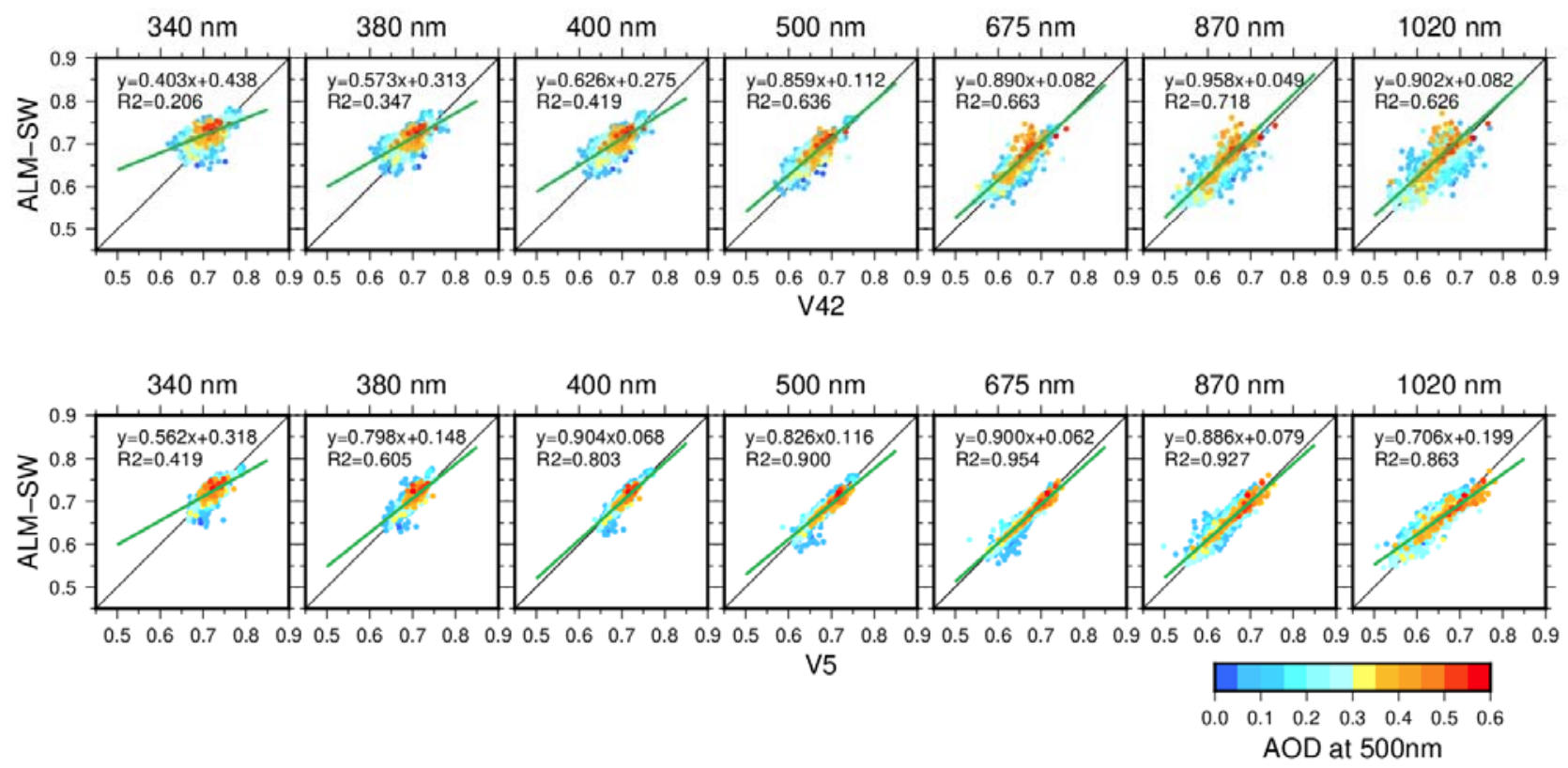

10 Figure S3: Comparisons of the asymmetry factor between ALM-SW, V42, and V5. Colors indicate the aerosol optical depth at 500 $n m$. " $y=a x+b "$ and "R2" are the linear fitting and the coefficient of the determination for the data of the aerosol optical depth more than 0.3 . 

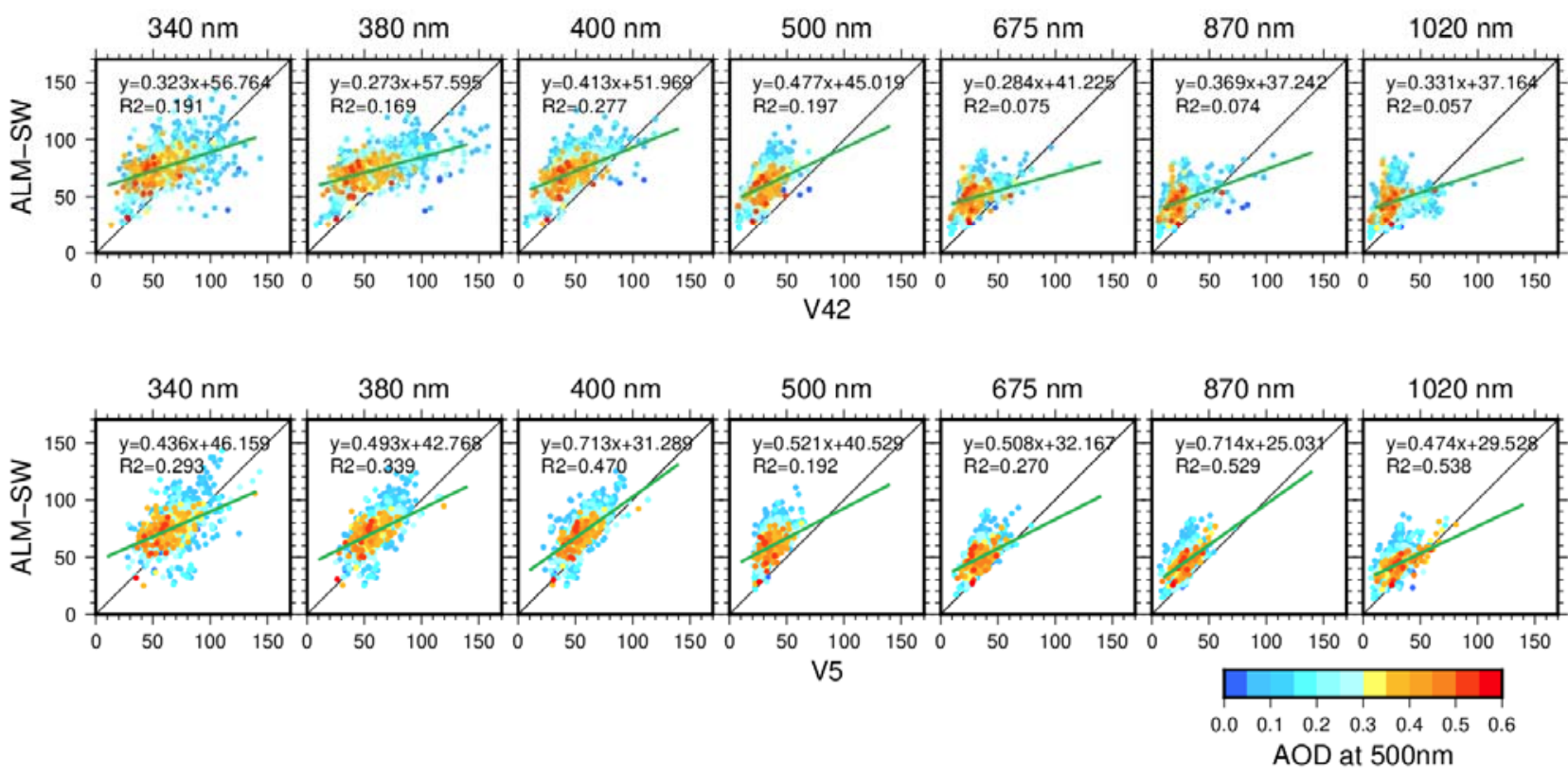

Figure S4: Comparisons of the lidar ratio between ALM-SW, V42, and V5. Colors indicate the aerosol optical depth at $500 \mathrm{~nm}$. 15 " $y=a x+b$ " and "R2" are the linear fitting and the coefficient of the determination for the data of the aerosol optical depth more than 0.3 . 